http://dx.doi.org/10.12795/PH.1989.v04.i02.25

\title{
PIERRE LOUŸS Y ANDALUCÍA: NUEVAS CARTAS INÉDITAS
}

\author{
Jean-Paul Goujon \\ $M^{a}$ del Carmen Camero
}

Presentamos aquí un cierto número de documentos inéditos destinados a completar el libro Pierre Loü̈s y Andalucía que publicamos en $1984^{1}$. Se trata de algunas cartas, que hemos podido descubrir en el transcurso de investigaciones ulteriores, y que, por su naturaleza, pueden contribuir a precisar determinados aspectos de las relaciones de Louÿs con Andalucía. Estos documentos aportan, en particular, un precioso suplemento de información biográfica: mientras que las dos estancias de Louÿs en Andalucía (1895 y 1896), comentadas por nosotros en la obra antes citada, eran ya conocidas, esta nueva serie de cartas inéditas vienen a ofrecernos la prueba de una tercera estancia del escritor en Sevilla, en 1903. Estancia jamás comentada por ninguno de los biógrafos de Louÿs ${ }^{2}$, y que muestra hasta qué punto la relación de éste con Andalucía, lejos de ser un simple momento «turístico» sin mañana, constituye, de hecho, un motivo recurrente de su vida.

En el plano literario propiamente dicho, no podemos afirmar que, durante sus tres estancias sevillanas, así como durante su larga estancia en Barcelona, en 1900, Louÿs mantuviera relaciones con escritores españoles. ¿Frecuentó su trato o amistad en París? Lo ignoramos, aunque no queda excluido que pudiera relacionarse con sudamericanos como Rubén Darío o, sobre todo, Enrique Gómez Carrillo $^{3}$. En todo caso, Louÿs no ignoraba la literatura española: un autor tan

1 Pierre Loü̈s y Andalucía-Cartas inéditas y fragmentos. Ediciones Alfar, col. Alfar/Universidad n. 8, Sevilla, 1984, 206 p.

2 Ni por Giorgio Mirandola (P. Loü̈s. Ed. Mursia, Milano, 1974), ni por el Dr. Robert Fleury (P. Loü̈s et A. Gilbert de Voisins, Ed. Tête de Feuilles, París, 1973), ni por el biógrafo más reciente, Dr. P. U. Dumont (P. Loü̈s l'ermite du Hameau, Ed. Libraidisque, Vendôme, 1985)

3 Enrique Gómez Carrillo, que publicó Sensaciones de París y de Madrid (1900) y El alma encantadora de París (1903, se encargaba de la sección de la Letras españolas en el Mercure de France, 
poco conocido en Francia como Bécquer le era hasta tal punto familiar que conocía de memoria, y en el texto original, algunos de sus poemas ${ }^{4}$. Por otra parte, notas inéditas del mismo Louÿs ${ }^{5}$ dan testimonio de que había estudiado a fondo La Celestina, obra que se complacía en comparar con la Satire sotadique de Luisa Sigea de Nicolas Chorier, así como con ciertas comedias de Corneille. En fin, Louÿs dominaba el español lo suficiente como para poder escribir en esta lengua, y de forma bastante correcta, faceciosas misivas a su amigo el pintor Paul Robert o a la actriz Musidora ${ }^{6}$.

A decir verdad, lo que Louÿs venía a buscar en Andalucía era menos una literatura extranjera que una cultura viva y un ambiente conveniente para su temperamento. Para él, los países del Sur constituían el cuadro más propicio para la creación literaria. En primer lugar favorecían la inspiración: la mujer (o mejor dicho la adolescente) latina o árabe representaba su ideal femenino, como podemos ver en Les Chansons de Bilitis (1895) y La Femme et le Pantin (1898). Se sabe, en efecto, que, aunque Bilitis sea supuestamente una Griega antigua, en realidad sólo se trata de la trasposición de una joven Oulad-Nail, Meryem-bent-Ali, amiga de Gide, a la que Louÿs había conocido en Argelia en $1894^{7}$. Es por otra parte significativo el hecho de que Louÿs haya excluido de su creación literaria tanto a la mujer italiana como a la griega moderna, aún siendo meridionales: el tipo árabe parece haber dominado sus preferencias hasta tal punto que, de toda España, sólo quiso retener a la andaluza ${ }^{8}$.

Segunda razón de esta elección geográfica: los países en los que Louÿs permaneció largas temporadas (Andalucía, Argelia, Egipto) son aquellos donde mejor podía trabajar y dedicarse a sus libros. Sabemos que Bilitis fue, si no concebido, al menos esbozado en Argelia en 1894, y que La Femme et le Pantin fue escrito en Sevilla y en El Cairo. Louÿs se complacía en repetir que la estancia en un país del Sur le proporcionaba, a la vez, la inspiración y el cuadro más propicio para escribir sus libros. Si tenemos en cuenta que después de su última creación novelesca, Les Aventures du Roi Pausole (1901), sólo realizó un muy breve viaje a Sevilla - por cierto, totalmente malogrado-, podemos pensar que su teoría no era en absoluto inexacta.

revista en la que colaboraba Louÿs. En 1904-1905, publicó precisamente en esta revista una encuesta sobre la joven literatura española, con respuestas de Unamuno, Emilia Pardo Bazán, Rubén Darío, etc. Señalemos, por otra parte, que en la misma revista aparecen elogiosas reseñas de los primeros libros de poemas de Juan Ramón Jiménez, Almas de Violeta y Ninfeas (noviembre de 1900, p. 560) y de Rimas (mayo de 1902, p. 551).

4 Cf. J. Cassou, «Souvenirs du Hameau de Boulainvilliers», in Bulletin des amis de P. Louÿs, n. 4 , sept. 1977 , p. 7.

5 Col. J.-P. Goujon.

6 Col. Dr. R. Fleury, Arcachon.

7 Cf. P. Iseler, Les débuts d'André Gide vus par P. Loü̈s, éd. du Sagittaire, Paris, 1938, pp. 108-110, y también A. Gide, Si le Grain ne meurt, in Journal-Souvenirs, Bibl. de la Pléiade, 1984, pp. 566-570 y $573-574$.

8 Se sabe que La Femme et le Pantin tuvo, durante mucho tiempo, como título primitivo L'Andalouse, y más tarde La Sévillane. 
Aunque Louÿs haya subtitulado La Femme et le Pantin, «roman espagnol», no pretendía de ningún modo escribir un libro pintoresco o «costumbrista». Las referencias a Sevilla y Cádiz, los detalles de costumbres, las descripciones que aparecen en la obra son tan sobrios como precisos, y no tienen un papel esencial en la economía del libro. Para Louÿs, esta novela es fundamentalmente la adaptación narrativa de un drama pasional que no tiene nada de específicamente andaluz: el drama de un hombre maduro enamorado de una mujer joven, que no lo ama y además se burla de él. Este tema de la «mujer fatal», que, del Romanticismo al Simbolismo, e incluso al Surrealismo, recorre toda la literatura moderna, había sido ya tratado en una obra por la que Louÿs sentía una enorme admiración y que constituye, a pesar de todo, una de las fuentes de la novela: Carmen; nos referimos, no al relato de Mérimée, sino a la ópera de Bizet.

Ahora bien, la rapidez y concisión del relato de Louÿs, el tono moderado y la discreción de su pintura de Andalucía, se oponen al llamativo libreto de Meilhac y Halévy. Se trataría más bien de una narración al estilo de Mérimée (escritor al que, curiosamente, detestaba Louÿs), que presenta, por otra parte, numerosas similitudes con Manon Lescaut de l'abbé Prévost. Sin embargo la crítica no parece haberse preocupado por subrayar estos asombrosos puntos comunes. Tanto en Prévost como en Louÿs, encontramos un idéntico tratamiento del personaje femenino: siempre visto y descrito según la óptica del narrador masculino, este personaje se nos muestra siempre en acción, sin ningún tipo de comentario por parte del autor. Louÿs va incluso más lejos que Prévost, ya que el último capítulo no propone ninguna moral, característica ésta que nos permite evocar el episodio de la Charpillon en las Mémoires de Casanova, fuente también de La Femme et le Pantin ${ }^{9}$. Otro punto en común con Manon Lescaut lo constituyen las reiteradas referencias a la inferioridad, tanto cultural como socio-económica, de la protagonista femenina (Manon; Concha) en relación con el personaje masculino (Des Grieux; Mateo Díaz).

No obstante, la literatura no es el tema dominante de las cartas inéditas que aquí presentamos. Se trata en general de impresiones de viaje, que se mezclan con consideraciones sentimentales o financieras más personales. De este grupo de documentos, conviene destacar en primer lugar las dos cartas escritas por Louÿs a su hermano, el diplomático George Louis, en $1895^{10}$. Estas cartas pueden completar el Journal de Voyage en Espagne escrito por Louÿs y su amigo Herold en la misma época y que hemos reproducido en nuestra anterior publicación ${ }^{11}$. La comparación de los dos textos pone al descubierto que, en más de una ocasión, Louÿs se sirvió de este Journal para escribir las cartas a su hermano; algunos pasajes son reproducidos textualmente.

9 «Sabes que la Charpillon es el documento histórico de Concha» [Pérez], escribía Louÿs a su hermano (carta sin fecha, col. particular, Bruselas).

10 Georges Louis (1847-1917), gran diplomático, ocupó primero un puesto en Egipto y fue más tarde embajador de Francia en Rusia, de 1909 a 1913.

11 Cf. op. cit., pp. 64-94. 
Para comprender bien la primera carta, es preciso recordar que Louÿs, en esa época, se encontraba en una situación económica difícil: creyéndose -erróneamente - tuberculoso, acababa de dilapidar la enorme herencia paterna, recibida en 1892, en apenas tres años. Su literatura, destinada a una élite, no podía mantenerlo económicamente. Además, sólo había publicado hasta entonces algunos opúsculos y Les Chansons de Bilitis, que acababan precisamente de salir cuando Louÿs se dirigió a Sevilla por primera vez. Los gastos de impresión de este libro, que se convertirá más tarde en uno de los más célebres del autor, y cuya tirada inicial fue de 500 ejemplares, habían sido adelantados por Georges Louis, su hermano, de quien dependerá económicamente durante casi toda su vida.

La segunda carta, escrita desde Carmona, constituye lo que podríamos llamar una búsqueda de las raíces. Georges Louis, que ocupaba entonces el puesto de delegado de Francia en la Comisión Internacional de la Deuda egipcia, vivía ya con la mujer con la que contraerá matrimonio en 1900: Paz de Ortega Morejón y Domínguez. Esta española era hija del cónsul general de España en Hamburgo, ciudad en la que nació en 1874. A petición de ésta y de su propio hermano, Louÿs se dirigió a Carmona, ciudad de origen de los Dominguez, con objeto de descubrir las huellas de la familia.

Esta búsqueda de la casa perdida tiene su importancia para Louÿs, que, siendo aún muy joven, se había quedado huérfano de madre y padre ${ }^{12}$, y había asistido con profundo dolor a la puesta en venta de la casa paterna ${ }^{13}$. Si a estos añadimos que, según los biógrafos de Louÿs más informados (R. Fleury, H. P. Clive), hay muchas posibilidades de que Georges Louis fuese en realidad no el hermano de Louÿs, sino su padre, no queda más que recurrir a la explicación psicoanalítica de la búsqueda de la casa por un ser. Habiendo perdido la casa paterna, Louÿs intentó exorcizar esta falta con la creación de una vida, la de la casa de los antepasados de la que se convertirá en su cuñada, es decir, muy probablemente, su segunda madre. Así se explica la precisión de esta carta, escrita desde Carmona, que presenta todas las características de un verdadero informe.

Mucho más anecdótica es la carta siguiente, dirigida al director del Hotel de París de Sevilla, para pedirle una capa española destinada al crítico Henri Albert. Es a éste último precisamente a quien va dirigida una carta escrita desde Cádiz, en septiembre de 1896, en la que la total ausencia de Andalucía se ve reemplazada por la literatura y los amores parisinos de Louÿs. Carta que debe situarse en el contexto de la segunda generación simbolista francesa (1894-1898) y de la revista Le Centaure, dirigida por el citado Henri Albert. Esta revista ${ }^{14}$ ocupa un lugar importante en la historia de la literatura francesa moderna, ya que, por una parte, contiene, en edición preoriginal, el célebre texto de Valéry La Soirée avec M.

12 Su madre murió en 1879, cuando el tenía 9 años, y su padre, en 1889 .

13 Cf. P. Louÿs, Lettre à G. Louis, 17 avril 1890, presentada por J.-L. Meunier, ed. A. l'Ecart, Muizon, 1985.

14 Le Centaure, que sólo tuvo dos números (1896), ha sido reeditado en «reprint» por Slatkine Reprints, en Ginebra, 1971. 
Teste, y por otra, fue el motivo de la desavenencia definitiva entre Louÿs y su amigo André Gide ${ }^{15}$.

Hemos añadido una carta a Debussy escrita desde Sevilla, carta que no es inédita, pero que no pudimos ofrecer en nuestro Pierre Louÿs y Andalucía, y que tiene el mérito de recordar los estrechos lazos que unían al poeta y al músico.

De turísticas, habría que calificar las cartas y fragmentos de cartas escritos a Georges Louis desde Sevilla en 1903. No tiene nada de sorprendente que la literatura ocupe aquí un mínimo espacio: en 1903, Louÿs se había apartado de la creación literaria o, más exactamente, había dejado de publicar obras importantes ${ }^{16}$. Hastiado por la literatura industrial y fácil, que estaba invadiendo periódicos y revistas, confundido por la aparición de nuevas corrientes literarias modernistas, sólo publicó, a partir de 1901 algunos artículos de revista, refugiándose en el estudio de la historia literaria, acumulando millares de notas y redactando múltiples estudios que, desgraciadamente, nunca publicará.

Son para él horas tristes, dominadas por incesantes problemas económicos, que no cesarán de acosarlo hasta su muerte, acaecida en 1925. Rehusando prostituir su pluma y escribir para el «gran público», Louÿs, al igual que sus amigos Gide y Valéry, permaneció fiel al ideal simbolista de los años 1890: el artista - y sobre todo el poeta- sólo debe escribir para un reducido número de personas y no publicar más que aquellas obras que estén lo suficientemente maduras, en ediciones cuidades, cuya tirada sea de una centena de ejemplares. Ideal que era también el de su maestro Mallarmé, que, como se sabe, publicó la primera edición colectiva de sus poemas en un lujoso libro, del que se tiraron sólo 47 ejemplares ${ }^{17}$.

La estancia de Louÿs en Sevilla en 1903 representa, pues, una huida y un intento por reencontrar los momentos de felicidad vividos ocho años antes. ¿No es significativo que el escritor decidiera volver a Sevilla en las mismas condiciones que en 1895 y 1896, es decir, soltero, dejando en Francia a su mujer, Louise de Heredia, con la que había contraido matrimonio cuatro años antes?. Sevilla se convirtió desde entonces para Louÿs en una ciudad quimérica, que sentía muy cercana, aunque ya no participara en su creación literaria: «Encantado de que hayas visto Sevilla bajo el sol», escribirá a su amigo André Lebey, hacia 1910. «Es la época en que está bella. Pero hay que volver en invierno para verla viva».

15 Ver al respecto P. Iseler, op. cit., pp. 113-117, y también Cl. Martín, La maturité d'André Gide. Tome I, De «Paludes» à «L'Immoraliste», 1895-1902. éd. Klincksieck, Paris, 1977, pp. 132-140 y $151-160$.

16 Su última obra importante es Les Aventures du Roi Pausole (Fasquelle, 1901), pero Louÿs no morirá, repitámoslo, hasta 1925 .

17 Les Poésies de Stéphane Mallarmé, éditions de la Revue Indépendante, Paris, 1887 (cf. Mallarmé, Oeuvres complètes, t. I, Poésies, éd. Barbier-Gordon Millan, éd. Flammarion, Paris, 1983, pp. 739-742. 


\section{I \\ CARTA A GEORGES LOUIS}

Sevilla, 11 de enero de 1895.

\section{Mi querido Georges:}

Acabo de realizar un viaje admirable, pero bastante terrible. El norte de España es, en este momento, una Siberia. Los ferrocarriles sólo avanzan siguiendo a toda una armada de excavadores de nieve, y anteayer por la mañana, llegué a Madrid con veintidós horas de retraso, después de cincuenta y cuatro horas de vagón (no me he parado en San Sebastían, que estaba blanco de nieve como Biarritz y Guéthary), de las cuales cuarenta y una horas las pasé en segunda sin calefacción y con el parqué como un lago de nieve fundida. Tenía el cuerpo bien abrigado, pero mis zapatos eran demasiado ligeros, así que tiritaba. Entre Zumárraga y Alsasua, en los Pirineos españoles, el tren se detuvo una vez durante dos horas y media a causa de un desprendimiento, la segunda vez, paramos tres horas debido a un pequeño alud, y por último, tuvimos que esperar otras tres horas soportando una tormenta de nieve tan fuerte, que el tren no osaba arriesgarse a pasar por un viaducto.

En Ávila, antes de atravesar la sierra de Guadarrama, hemos tenido una avería, que ha durado desde las 9 de la mañana hasta las 7 de la tarde.

Y en la sierra, hemos estado desde las 10 de la noche hasta la 1 de la madrugada sin poder avanzar ni retroceder, a 1.300 metros de altitud, y con un frío de perros, que hacía castañear los dientes. En cuanto dejó de nevar, la luna, en lo alto, parecía algo milagroso. No he visto nada tan bello desde la travesía del Djurdjura $^{1}$, en julio. Pero temblaba de frío, y también un poco de miedo, porque la única salida que veía a esta aventura era una pleuresía.

Tranquilízate, no tengo nada. ¿Cómo? No me lo explico. Dos días y dos noches expuesto a las corrientes de aire de un vagón (de segunda, pero mucho peor que la tercera en Francia), sin calefacción, con los asientos duros, jlos cristales rotos!, el parqué inundado (no exagero), y como resultado, ni siquiera un poco de fiebre. Sólo un cansancio, que ya se va pasando, y un poco más de tos, que también comienza a desaparecer ${ }^{2}$.

Sevilla es el paraiso. Un cielo de junio, palmeras, naranjos, todo el mundo sin abrigo y, en las habitaciones, las calefacciones apagadas. Me he quedado estupefacto al ver hasta qué punto los Españoles se parecen a los grabados 1830 o a los vestidos de Carmen ${ }^{3}$. Las mujeres son horribles o espléndidas ${ }^{4}$.

1 Montaña cerca de Argel, que Louÿs había visitado en julio de 1894 cuando se dirigía a Biskra, con objeto de encontrarse allí con Meryem-bent-Ali, joven Oulad-Nail, que le había sido recomendada por su amigo Gide.

2 Todo esta pasaje se encuentra, ligeramente modificado, en el capítulo IV de La Femme et le Pantin, titulado Apparition d'une petite moricaude dans un paysage polaire.

3 Alusión a los grabados de Gustave Doré y a la ópera de Bizet.

4 Las mismas frases aparecen en el Journal de Voyage en Espagne, fechadas el 10 de enero de 1895, es decir un día antes de esta carta a Georges Louis (cf. nuestro Pierre Louÿs y Andalucia, p. 66). 
No hay término medio, es más cómodo. Pero las horribles están en mayoría. Otro día que me encuentre más descansado, te contaré más cosas de Sevilla.

Mi ignorancia total de la lengua me fastidia más de lo que pensaba ${ }^{5}$.

He cogido una habitación orientada al sur, en una plaza, para tener aire y sol. Está en una casa que pertenece a un hotel ${ }^{6}$ adonde voy a comer, porque hacen cocina francesa, y la española no gustaba a mis intestinos. ¿Qué cascajo estoy hecho! El total (comida y cama) cuesta 12,50 al día, es demasiado. (Tranquilízate, no se admiten señoras).

Es demasiado. En cuanto sepa un poco de español, cogeré una habitación más barata en casa de algún sevillano.

Calculo que podré arreglármelas con ocho francos. Estoy sin un duro, como siempre. Me había traído libros para tres meses, pues esperaba trabajar mucho aquí ${ }^{7}$.

(...) Antes de partir, había comenzado una novela (¡moderna!) ${ }^{8}$ con tanto entusiasmo que la primera tarde escribí veintisiete páginas ${ }^{9}$. Trata de una niña. Me encuentro rodeado de libros sobre la psicología infantil, y me gustaría contar la historia de una niña, que se llamaría Niche, Nichette, Nichinette, Toiniche, Toinon, Toinette, (espero que Marguerite no se enfade), desde su nacimiento hasta los siete años, edad con la que muere. La novela está narrada por el padre, y es menos la historia de un niño, que las impresiones de un hombre que tiene un niño. Hay que matizar.

Tengo que escribirla ahora, porque si me caso, dirían que escribo la historia de mi mujer y de mi hija, y eso siempre es delicado ${ }^{10}$.

¡Uf!, larga carta. Voy a llevarla a correos y a comprar de la tinta azul de la tinta violada et un cuaderno ${ }^{11}$, pero esta tarde no escribiré.

Me acostaré, como ayer, a las nueve y media.

Te abrazo de todo corazón.

Pierre.

5 Louÿs no tardará, sin embargo, en dar clases particulares de español, realizando grandes progresos.

6 En el Journal de voyage en Espagne, con fecha del mismo día (cf. op. cit. p. 68), Louÿs da su dirección: Plaza del Pacífico no 9, Sevilla (actualmente Plaza de la Magdalena). Podemos suponer que se trataba de una habitación perteneciente al Hotel de París, situado en la misma plaza (cf. catálogoexposición SEVILLA EN LA TARJETA POSTAL ANTIGUA (1895-1928), Monte de Piedad y Caja de Ahorros de Sevilla, donde se reproduce una vista de la Plaza del Pacífico hacia 1907).

7 En realidad, Louÿs sólo escribirá algunas nuevas Chansons de Bilitis, que serán incluidas en la segunda edición de este libro, aparecido en 1898.

8 Roman moderne: en relación con sus dos anteriores libros «antiguos»: Les Chansons de Bilitis y Aphrodite (1896, que entonces estaba terminando).

9 Se trata de la novela inacabada titulada Nichette, de la que existe un manuscrito, aún inédito, de 32 páginas, fechado el 2 de enero de 1895 (cf. catálogo 256 (1929) de la Librería Blaizot, Paris, n. 5763$)$.

10 Louÿs no se casará hasta 1899 , es decir cuatro años más tarde. 
Carmona, 5 de marzo del 95.

\section{Mi querido Georges:}

No hay ninguna tumba Domínguez en la iglesia del Carmen. Es una pequeña iglesia blanca, situada en las puertas de la ciudad, al final de la calle de Sevilla. Sólo existen tres lápidas, de las que la más reciente data de 1850; la señora que cuida la iglesia afirma que nunca ha visto enterrar allí a nadie. No sé de dónde puede provenir este error.

Carmona es una ciudad blanca, ascendente y alegre. Sus calles estrechas y el estado de las casas, cuyas columnas y molduras desaparecen bajo la cal, me han recordado mucho la Kasbah de Argel ${ }^{12}$. Una vieja puerta morisca, en el centro de la ciudad contribuye también a este parecido. De lejos, Carmona aparece con una doble pendiente sobre dos colinas, dominada por una torre de ladrillos, construida según el modelo de la Giralda. Evidentemente, nada ha cambiado desde que Mme Ortega se marchó ${ }^{13}$.

He visto la casa Domínguez en el no 12 de la calle de Palomar. Una puerta alta y negra, con manpostería roja alrededor, preciosas ventanas con rejas verdes, una ventana blanca por encima de la puerta con un pequeño tejado, y, en todo lo alto, un campanario azul con pilares. He entrado en el portal; he visto, a la izquierda, un pequeño patio muy sombreado y, a la derecha, un patio muy bien cuidado, con macetones de plantas verdes entre sus columnetas de mármol. Todo estaba limpio, blanqueado, lavado, pero la idea de que se trataba de una casa perdida para alguien, me daba una enorme impresión de tristeza, a pesar de su tranquilidad y su luminosidad.

La casa Rueda es más sombría y más monumental. Las paredes están cubiertas por anchos adornos moriscos de arcilla; la puerta está flanqueada por columnas de piedra y tiene encima un escudo esculpido así: [dibujo]. Se trata, como me decías, de la casa del Ayuntamiento, sobre cuyos muros puede leerse el siguiente aviso: «De orden del señor Alcalde se prohibe verter aguas en este sitio, bajo la multa de 2 pesetas» ${ }^{14}$.

He paseado después por las calles, asombrándome siempre por su blancura, habituado como estoy a las paredes rosas, amarillas, azuladas de Sevilla ${ }^{15}$. Los hombres llevan aún la chaqueta corta, el sombrero cordobés y la capa negra y

11 En español en el texto original.

12 Allí se encontraba Louÿs en julio de 1894 (cf. supra, nota 1).

13 Madre de Paz de Ortega Morejón y Domínguez, Mme. de Ortega se convertirá en 1900 en la suegra del hermano de Louÿs.

14 En español en el texto original.

15 Encontramos expresiones parecidas en La Femme et le Pantin (ed. de 1898, p. 39). 
roja. Las mujeres cubren sus cabellos con un pañuelo multicolor, y su cuerpo con un gran mantón, que me recuerda a la almalafa.

Al pasar ante una puerta abierta, he visto, ocupando el puesto de honor de una pobre habitación, un gran retrato de M. Carnot ${ }^{16}$. Es lo único que me ha recordado el clima del Sena en este bello país africano.

En fin, aquí estoy, en una «huéspedes», escribiéndote esta carta en una mesa con brasero, junto a un gatito adormecido y una chica andaluza que hace como que lee.

Te abrazo de todo corazón.

Pierre.

III

CARTA A CLAUDE DEBUSSY

[Sevilla, primeros de septiembre, 1896]

¿Que se cuenta por París, y qué hace el más ilustre de los Claudes? ${ }^{17}$.

En la más rosa de las Sevillas, corrompo a las chiquillas. Pero también trabajo, ¡demonio! ${ }^{18}$. ¡Vamos a trabajar!, como dice M. Coquelin ${ }^{19}$.

$\mathrm{Tu}$

P.L.

16 Sadi Carnot, presidente de la Republica Francesa de 1887 a 1894, fue asesinado el 23 de junio de 1894 en Lyon por el anarquista Caserio, acontecimiento que podría explicar la presencia de este retrato de Carnot, nueve meses después de su muerte.

17 Carta reproducida en Correspondance de Claude Debussy et de Pierre Louÿs, ed. H. Borgeaud, Corti, Paris, 1945, pp. 81-82. Debussy, que, de 1893 a 1904, fue uno de los más íntimos amigos de Louÿs, sufría por aquel entonces dificultades económicas particularmente graves y se encontraba muy desalentado.

18 En efecto, Louÿs acababa de escribir las 60 primeras páginas de La Femme et le Pantin.

19 Constant Coquelin, célebre actor francés de la época. 
Cádiz, 6 de septiembre [de 1896] ${ }^{20}$.

\section{Querido:}

Desgraciadamente he olvidado mis notas de cuentos en París ${ }^{21}$. ¿Es verdad que el Centaure se publica? y ¿para cuándo necesitaría usted algo?.

Ya sabe que tengo tres sonetos definitivamente acabados ${ }^{22}$ y que me sentiría muy dichoso si le GUSTASEN...

Gracias por su reseña de Fliegen $^{23}$. Aún no he respondido al autor, pero no tardaré en hacerlo.

Tengo noticias suyas por Blanche ${ }^{24}$; esta chica es encantadora, pero un poco pelma; ¿no podría usted quitármela durante mi ausencia?, le haría un gran favor a su amigo.

\section{P.L.}

Si quitármela no le dice nada, ¡haga que al menos me la quite otro! Si no, la historia Stella ${ }^{25}$... se repetirá conmigo, y, como usted sabe, no me gusta nada esa clase de deporte.

A pesar de todo, no convendría enseñarle esta carta.

20 Col. M. Binazzi, Paris.-Henri Albert, cuyo verdadero nombre era Henri-Albert Haug (1868-1921), fue el primer y principal traductor francés de Nietzsche, cuyas obras completas comenzó a publicar, a partir de 1895, en el Mercure de France. Muy relacionado con cantidad de escritores y artistas, dirigió en 1895 el suplemento francés de la revista alemana Pan, y al año siguiente, Le Centaure, importante revista en la que colaboraron Louÿs, Régnier, Tinan, Valéry, etc.

21 Se trata de Les Sept Douleurs, libro de cuentos, cuya publicación había sido anunciada por Louÿs, pero de hecho sólo escribirá cinco, que, bajo el título Le Crépuscule des Nymphes, serán publicados en las ediciones Montaigne en abril de 1925, o sea dos meses antes de su muerte.

22 Les Hamadryades, serie de tres sonetos de Louÿs, que, en efecto, serán publicados a finales de 1896 en el no 2 del Centaure.

23 La revista alemana Fliegen Blätter (Munich), que había publicado un artículo sobre Aphrodite.

24 Blanche-Marcelle, joven frívola, que Louÿs y sus amigos Albert, Tinan y Lebey frecuentaban por entonces en el Quartier Latin.

25 Estelle, llamaba Stella: otra joven del Quartier Latín, que perseguía al poeta André Lebey, amigo de Louÿs, por quien sentía una pasión arrolladora e insoportable. Fue precisamente para curar a Lebey de esta pasión por lo que Louÿs escribió Le Femme et le Pantin, novela que aparece, por otra parte, dedicada a éste. 
Muy Sr. mío:

Había prometido a uno de mis amigos ${ }^{27}$ llevarle una capa española y lo he olvidado. ¿Tendría usted la amabilidad de enviar a uno de sus mozos a comprar una, en la calle Tetuan, por el precio de 60 pesetas? Convendría que la cinta fuese amarillo oscuro. Lo mejor sería que me la enviase contra reembolso, si es posible. Si no, le enviaría el dinero por cheque, incluidos los gastos.

Le quedaría realmente agradecido si pudiera ocuparse de este pequeño encargo. Mis más distinguidos saludos.

\section{Pierre Louÿs \\ Il rue de Chateaubriand París \\ (Dirección para el envío)}

\section{VI \\ CARTA A GEORGE LOUIS}

Sevilla, sábado 18 [de abril de 1903] ${ }^{28}$.

(...) Sevilla está a rebosar y los precios, desorbitados. Me alojo en una habitación de servicio, enladrillada, sin armario, ni cómoda, ni ropero, ni cortinas y situada justo bajo el tejado. Me ahogo aquí tanto de día como de noche. 35. a la sombra. He pasado, antes de llegar a este lugar, por once hoteles, todos completos del sótano al desván... Ayer por la tarde me pusieron, a la fuerza, en una mesita en la que se encontraban dos médicos franceses, que, al ver en una botella el nombre de López y Heredia, han comenzado una mordaz crítica de $\mathrm{H}$ [eredia] ${ }^{29}$. En tono muy seco, los mandé callar sin darme a conocer. Me pidieron disculpas y no volvieron a abrir la boca. En fin, todo esto prueba una cosa, que no hay que venir aquí en esta época, como hace todo el mundo. (...)

26 Colección particular, París.

27 Henri Albert (cf. supra, nota 20), que había escrito a Louÿs una carta el 11 de septiembre de 1896 (col. Godoy, Lausanne), le pidió, en efecto, que le trajera una capa española.

28 Col. part., París.

29 El célebre poeta José María de Heredia (1842-1905), autor de Les Trophées (1893). Louÿs se casó en 1899 con su hija Louise, después de haber sido el amante de Marie, hermana de ésta, casada en 1895 con el poeta simbolista Henri de Régnier. 
VII

\section{CARTA A GEORGES LOUIS}

Sevilla, miércoles 22 [de abril, de 1903]

(...) Sevilla ha cambiado. El Crédit Lyonnais, que había desfigurado ya nuestro boulevard des Italiens, ha hecho otro tanto con la Sierpes- Y además el local de las bailaoras ${ }^{30}$ ha desaparecido. Y además, hay tranvías y troles por todas partes. Y además... y además... ¡Qué triste es volver a ver los lugares en los que uno ha sido feliz!... (...)

\section{VIII \\ CARTA A GEORGES LOUIS}

Viernes 24 [de abril de 1903] ${ }^{31}$.

Si las cartas que te escribo fueran por el rápido París-Arras, que alcanza 98 Kil. por hora, o por el rápido París-Amiens, que alcanza 99, las recibirías al día siguiente por la mañana, puesto que no hay más que quinientas leguas entre Sevilla y París, pero estamos en España, país en el que no se conocen tales velocidades; hasta esta mañana, no he recibido tu carta del lunes y me asombra que en esa fecha, aún no tuvieses noticias mías.

Te escribí el sábado, creo (y una o dos veces después); mi carta fue por el tren correo que marcha a 30 kilómetros por hora. Tardó 19 horas en llegar a Madrid. Allí descansó durante 14 horas (de las 6,25 de la mañana hasta las 8,20 de la tarde). Después de haber dormido bien, volvió a salir en su pequeño tren hasta la frontera- supongo que habrá llegado, pero no sé nada.

Te escribo durante una tormenta de granizo. Llueve a cántaros, y por primera vez, desde el invierno. Hace frío, toso, tengo cogido el pecho hasta la cintura, me veo obligado a tomar quinina y ponerme yodo. Imposible salir después de las 5 de la tarde, es decir, en el momento en que Sevilla está más encantadora. Nunca he hecho un viaje más desafortunado que éste.

Sin embargo, estoy contento porque adoro Sevilla y me consuelo diciéndome que, en mi próximo viaje, quizás sea más dichoso. (...)

30 Col. part., París. El Burrero, situado en la calle Sierpes, lugar que Louÿs frecuentaba durante su estancia en Sevilla en 1895 (cf. Pierre Loü̈s y Andalucía, op. cit. pp. 78-80, p. 114 y p. 126).

31 Col. part., París. La carta y el sobre llevan grabados el siguiente encabezamiento: HOTEL DE INGLATERRA-PLAZA SAN FERNANDO-SEVILLA, hotel en el que Louÿs encontró finalmente una habitación. 